\title{
Role of Triple Phase Computed Tomography in the Evaluation of Liver Lesions
}

\section{ABSTRACT}

Introduction: Wide range of benign and malignant tumours can occur in the liver, the largest organ in our body. So far, the histopathological diagnosis was considered the gold standard with the limitation of it being invasive. However, the advances in the radiological imaging techniques would surpass this difficulty, as well helps in coming to a close, if not many times the definitive diagnosis, thus preventing these invasive diagnostic procedures.

Aim: To assess the role of triple phase Computed Tomography (CT) in the evaluation of liver lesions by evaluating the enhancing characteristics and comparing the findings with ultrasound, Magnetic Resonance Imaging (MRI), Biopsy and follow-up as applicable during the study period.

Materials and Methods: This is a longitudinal prospective study conducted at Kamineni Institute of Medical Sciences, Narketpally, on 60 selected subjects for a period of 12 months, during July 2017 to July 2018. Patients of age more than 20 years of both gender with clinical suspicion or inconclusively diagnosed liver lesions were selected. These patients are evaluated using standard triple phase contrast CT liver protocol on 16 slice multidetector CT scan. The different enhancing patterns were inspected and compared to USG, MRI and Biopsy as applicable. All the collected data were tabulated in Microsoft excel sheet and were analysed in SPSS Software version 21.

Results: The study consisted of 60 patients with 35 male and 25 female and assessed a total of 200 individual liver lesions.
Out of which, 141 were malignant and 59 benign. Metastasis being the most common $(n=113)$, followed by Hepatocellular Carcinoma $(\mathrm{HCA})(\mathrm{n}=26)$ and intrahepatic Cholangiocarcinoma $(C C A)(n=2)$ in malignant lesions and Haemangioma $(n=26)$ was the commonest benign lesion followed by cysts $(n=20)$, abscess $(n=10)$, Focal Nodular Hyperplasia $(F N H)(n=2)$ and adenoma $(n=1)$. In total, there were $112(56 \%)$ hypovascular lesions and 88 hypervascular lesions (44\%), with 11 enhancement patterns which are correlated to standards of reference satisfactorily. The study shows triple phase CT is $100 \%$ sensitive in diagnosing abscess, simple cysts, FNH and intrahepatic CCA and showed varied sensitivities with other lesions like HCC (sensitivity-79\%), Haemangioma (sensitivity-92.3\%), Metastasis (sensitivity$91.1 \%$ ), however, it showed $100 \%$ specificity in diagnosing all the cases when there was typical enhancement pattern for the individual lesion concerned. The four benign enhancement patterns and five malignant enhancement patterns were noted along with hypo/hypo/hypo, hypo/hypo/hyper and hyper/A/A patterns which needs cautious interpretation.

Conclusion: We recommend triple phase CT scan as a standard first line procedure with high sensitivity, specificity and accuracy in differentiating benign and malignant liver lesions and avoiding unnecessary biopsies. Hepatic Arterial Phase (HAP) is used in identifying small hypervascular lesions and Porto-Venous Phase (PVP) in detecting small hypovascular lesions. Particularly in HCC, triple phase CT provides additional information of vascular invasions, arterioportal shunts, capsular delineation and vascular road map for pre-surgical evaluation.

Keywords: Cholangiocarcinoma, Delayed phase, Focal nodular hyperplasia, Haemangioma, Hepatic arterial phase, Hepatocellular carcinoma, Metastasis, Portovenous phase

\section{INTRODUCTION}

Liver is the largest visceral structure located in right hypochondriac region with dual blood supply i.e., $75-80 \%$ from portal vein and 20-25\% from hepatic artery [1]. The major functions are digestion, detoxification and thus maintaining the physiological equilibrium. It is prone to several benign and malignant liver lesions.

The primary malignant lesions and metastatic lesions in liver are supplied predominantly by hepatic artery, where normal parenchyma is predominantly supplied by portal blood [2]. This differential blood supply forms the basis for the triple phase CT scan of liver. Due to good number of both benign and malignant liver lesions and predominant being benign lesions, it is very essential to differentiate these lesions on non-invasive imaging modality in diagnosing, prognosticating, designing proper therapeutic strategies, preventing unnecessary invasive biopsies [3] and finally in follow-up [4] evaluation and palliative care.

Triple phase CT scan of liver with the Hepatic Arterial Phase (HAP), Porto venous phase and Delayed Phase (DP) helps in discriminating the vascular supply to the different liver lesions, thus characterising them further into benign and malignant lesions based on characteristic contrast uptake. It also helps in defining the vascular invasion, capsular delineation which further helps in characterising the lesions.

The non-invasive radiological investigative procedures help in characterising the tumours into benign and malignant in a very efficient manner and the present study aimed at comparing the findings of triple phase computed tomography with the ultrasonography, MRI and Biopsy findings.

\section{MATERIALS AND METHODS}

The present study is a longitudinal, prospective study with 60 selected subjects [200 lesions] conducted at Kamineni Institute of Medical Sciences, Narketpally for a period of 12 months, during July 2017 to July 2018, after taking proper informed consent in the patient's native understandable language and obtaining the Institutional Ethical Committee clearance (Ref.No. ETHICS COMMITTEE/KIMS/ NKP/2017).

Inclusion criteria: Patients of age more than 20 years of both gender with the clinical suspicion of liver lesion or previously detected liver lesion on ultrasound, conventional CT or biopsy were selected for the study. 
Exclusion criteria: Patients for whom contrast is contraindicated like renal failure,previous contrast reactions and pregnant mothers and patients with blunt trauma which may cause architectural changes in liver were excluded from the study.

These patients are evaluated using standard triple phase contrast CT protocol on Toshiba Alexion 16 slice multidetector CT scan. The different enhancing patterns were inspected and compared to USG, MRI, Biopsy and follow-up as applicable during study period.

Routine antero-posterior (AP) topogram of the abdomen will be taken initially in all patients in supine position with breath holding. Axial sections of $5 \mathrm{~mm}$ thickness will be taken from lung bases to ischial tuberosity. Initial plain scan is performed followed by intravenous contrast study. Enhancement of each lesion in each phase was evaluated and results were tabulated according to 11 enhancement patterns. Sagittal, coronal reconstruction and curved planar reformatting, volume rendering, maximum and minimum intensity projections were done as required and reviewed directly on display console.

For contrast study, 18G vasofix (indwelling catheter) is used, access through antecubital vein and dynamic injection at a rate of 80-100cc of non-ionic contrast (OMNIPAQUE; IOHEXOL) at $350 \mathrm{mg}$ iodine/ $\mathrm{ml}$ concentration will be given using power injector. Sections will be taken in HAP at 22-27 seconds, Portal Venous Phase (PVP) at 4060 seconds and DP at 5-8 minutes in cranio-caudal direction from superior to inferior margin of liver. Post-study reconstruction will be done at $2.5 \mathrm{~mm}$ [Table/Fig-1].
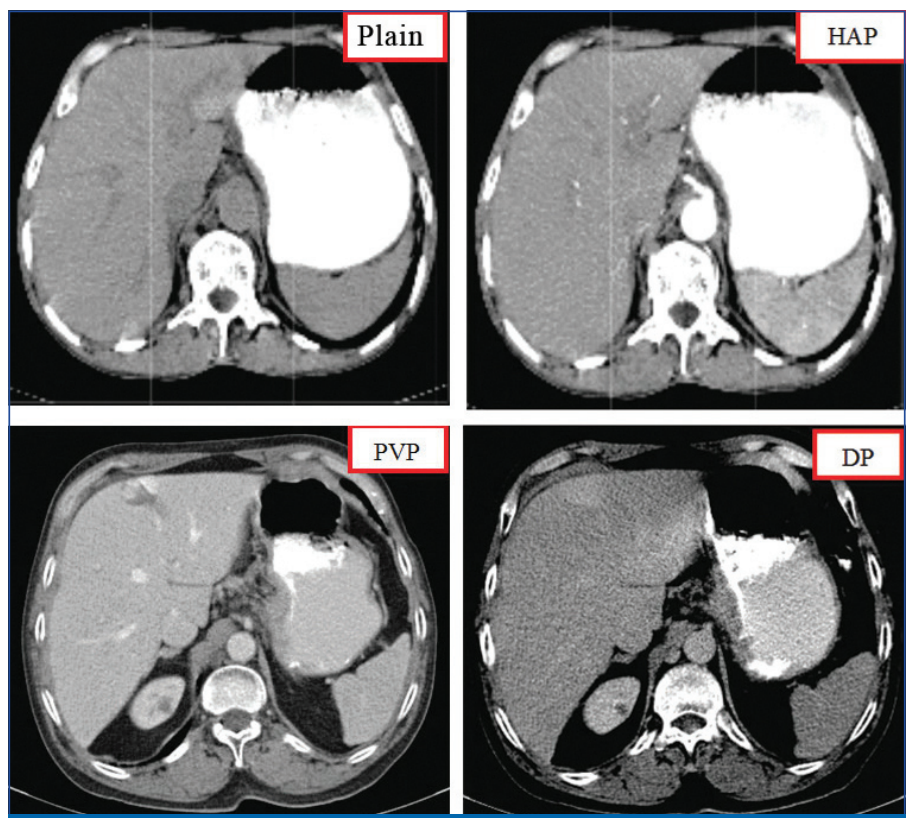

[Table/Fig-1]: Illustration of "NORMAL" phases of Triple phase CT scan liver. Normal Phases in Triple phase contrast Computed tomography of Liver: 1. Unenhanced (Plain); 2. Hepatic arterial phase (HAP); 3. Portal venous phase (PVP); 4. Delayed phase (DP)
Images were interpreted by two experienced radiologists of 5 years and 7 years' experience on their respective Picture Archiving and Communication System (PACS) after getting proper reconstructed images in all the different phases of liver study-Unenhanced, HAP, PVP and DPs. CT appearance of each lesion in each phase is characterised based on enhancement patterns and attenuation compared to liver parenchyma in that phase. Lesions were broadly categorised into hypervascular lesions and hypovascular lesions compared to surrounding parenchyma. Later, the nature of lesions confirmed by biopsy/USG/MRI/Follow-up as applicable. Lesions showing no change in size after a minimum of six months were presumed to be benign.

Based on the attenuation and homogeneity of the lesion compared to surrounding liver parenchyma in that phase, liver lesions are characterised into one of these five types:

- Homogenous, water attenuation: Hypo (Cyst)

- Slightly in homogenous, soft tissue attenuation: Hypo

- Mixed attenuation but hypo attenuation than the arterial system: Mixed

- Hyper attenuation but less than arterial system: Hyper

- Iso attenuation to the arterial system: Arterial /A

The pattern of enhancement is a three pattern name that includes the appearance in each phase (e.g., hypo/hypo/hypo). Additional patterns of subtype enhancement in arterial phase like peripheral puddles, variegated, continuous hyper attenuating rim, incomplete rim and cleft were also considered.

\section{STATISTICAL ANALYSIS}

The findings from each modality were tabulated on an excel sheet and data was statistically analysed using SPSS software version 21.

\section{RESULTS}

The present study consists of selected 60 patients of both gender with age ranging between 20 to 80 years. Males were 35, females were 25 and predominant age group is 50-60 years [Table/Fig-2]. Male preponderance was seen in cases of metastasis (60\%), HCC (83\%) and liver abscess (100\%). Female preponderance was seen in cases of haemangioma (80\%), simple cyst (75\%) and focal nodular hyperplasia (100\%) and hepatic adenoma (100\%).

In the 60 patients studied, there were 200 lesions in total. A total of 39 patients/141 lesions were malignant lesions (67\%) and 21 patients/59 lesions were benign (33\%) [Table/Fig-3]. The most common malignant lesion being metastasis in $41 \%$, most common primary malignant lesion being HCC in $20 \%$ of patients. A $60 \%$ of metastasis was seen in 51-60 age groups, most common primary being lung carcinoma and second being stomach carcinoma. The youngest was 32 years old female and oldest was 76 years old male. $66.6 \%$ of $\mathrm{HCC}$ were seen in 51-60 years age group with the youngest at 45 years and oldest at 65 years. Intrahepatic Cholangiocarcinoma is seen in 2 patients (100\%) in the age group 51-60.

\begin{tabular}{|c|c|c|c|c|c|c|c|c|c|c|}
\hline \multirow[b]{2}{*}{ Liver lesions (benign and malignant) } & \multicolumn{6}{|c|}{ Age groups } & \multirow[b]{2}{*}{ Total } & \multirow[b]{2}{*}{ Percentage (\%) } & \multicolumn{2}{|c|}{ Gender } \\
\hline & $21-30$ & $31-40$ & $41-50$ & $51-60$ & $61-70$ & $71-80$ & & & Male & Female \\
\hline Simple cyst & 0 & 1 & 3 & 0 & 1 & 0 & 5 & 8.33 & 1 & 4 \\
\hline Abscess & 1 & 0 & 2 & 0 & 0 & 0 & 3 & 5 & 3 & 0 \\
\hline Haemangioma & 0 & 2 & 6 & 1 & 1 & 0 & 10 & 16.66 & 2 & 8 \\
\hline $\mathrm{FNH}$ & 0 & 0 & 2 & 0 & 0 & 0 & 2 & 3.33 & 0 & 2 \\
\hline Hepatic adenoma & 0 & 0 & 1 & 0 & 0 & 0 & 1 & 1.66 & 0 & 1 \\
\hline $\mathrm{HCC}$ & 0 & 0 & 1 & 8 & 3 & 0 & 12 & 20 & 10 & 2 \\
\hline Metastasis & 0 & 1 & 3 & 15 & 5 & 1 & 25 & 41.66 & 17 & 8 \\
\hline Intrahepatic CCA & 0 & 0 & 0 & 2 & 0 & 0 & 2 & 3.33 & 2 & 0 \\
\hline Total & 1 & 4 & 18 & 26 & 10 & 1 & 60 & 100 & 35 & 25 \\
\hline
\end{tabular}




\begin{tabular}{|c|c|c|}
\hline Groups & No. of cases & No. of Lesions \\
\hline Benign & 21 & 59 \\
\hline Malignant & 39 & 141 \\
\hline Total & 60 & 200 \\
\hline \multicolumn{3}{|c|}{$\begin{array}{l}\text { [Table/Fig-3]: Frequency of benign and malignant cases and lesions in the study } \\
\text { population ( } \mathrm{n}=60) \text {. } \\
\text { *In present study, malignant lesions more than benign lesions }(67 \%>33 \%)\end{array}$} \\
\hline
\end{tabular}

Haemangioma was the most common benign lesion accounting to $16 \%$, followed by simple cyst (8\%) and abscess (5\%). Two patients of $\mathrm{FNH}$ were diagnosed in 41-50 age group (3.3\%).

Based on enhancement patterns of individual lesions, they are grouped into hypo/hypervascular lesions. In the present study, there were 112 hypovascular lesions accounting for $56 \%$ of the total lesions ( $n=200$ ), they were 88 hypervascular lesions accounted for $44 \%$ of the total liver lesions [Table/Fig-4].

\begin{tabular}{|c|c|c|}
\hline Groups & No. of Lesions & Percentage (\%) \\
\hline Hypovascular lesions & 112 & 56 \\
\hline Hypervascular lesions & 88 & 44 \\
\hline Total & 200 & 100 \\
\hline \multicolumn{3}{|c|}{$\begin{array}{l}\text { [Table/Fig-4]: Frequency of hypovascular and hypervascular lesions in the } \\
\text { present study. } \\
\text { *In present study, hypovascular lesions are more than hypervascular lesions }(56 \%>44 \%)\end{array}$} \\
\hline
\end{tabular}

The most common malignant hypovascular lesion included metastases $(n=80)$ accounted for $71.42 \%$ of total hypovascular lesions arising from lung carcinoma, gastric carcinoma, and colorectal carcinoma. Benign hypovascular lesions were cysts $(n=20) 17.85 \%$ and Abscess $(n=10)$ 9.0\%.

Most common benign hypervascular lesions was Haemangioma $(n=24)$ accounted for $27 \%$, followed by $\mathrm{FNH}(\mathrm{n}=2)$ accounted for $2.2 \%$. While the most common malignant hypervascular lesions were metastasis ( $n=33$ ) accounted for $37 \%$, from pancreatic cancer, cervical cancer, and gall bladder cancer. Other malignant lesions were HCC $(n=26) 29 \%$, and intrahepatic cholangiocarcinoma for $(n=2)$ 2.2\% [Table/Fig-5].

\begin{tabular}{|l|c|c|}
\hline Hypovascular lesions & No. of lesions & Percentage (\%) \\
\hline Simple cyst & 20 & 17.8 \\
\hline Abscess & 10 & 9 \\
\hline Hemangioma & 02 & 1.8 \\
\hline Metastasis & 80 & 71.4 \\
\hline Total & 112 & 100 \\
\hline Hypervascular lesions & No. of lesions & Percentage (\%) \\
\hline Haemangioma & 24 & 27.3 \\
\hline FNH & 02 & 2.3 \\
\hline Adenoma & 01 & 1.1 \\
\hline HCC & 26 & 29.5 \\
\hline Intrahepatic CCA & 02 & 2.3 \\
\hline Metastasis & 33 & 37.5 \\
\hline Total & 88 & 100 \\
\hline [Table/Fig-5]: Frequency of different hypovascular and hypervascular lesions. \\
*Metastasis is the predominant hypovascular lesions with 71.4\% of cases; Metastasis, HCC and \\
Hemangioma are the predominant hypervascular lesions with 37.5\%, 29.5\% and 27.3\%, cases \\
respectively \\
FNH: Focal nodular hyperplasia; HCC: Hepatic carcinoma; CCA: Cholangiocarcinoma
\end{tabular}

In patients with hypovascular lesions, a significant difference was seen in the number of lesions detected between the PVP and other phases when the lesions were $<1 \mathrm{~cm}$ and $1-3 \mathrm{~cm}$ in size. When the lesion size was $>3 \mathrm{~cm}$, similar numbers were seen on all phases. The conspicuity of hypovascular lesions were higher on the PVP than on any other phase when the lesions were $<1 \mathrm{~cm}$ and $1-3 \mathrm{~cm}$ in size.

In patients with hypervascular lesions, a large number of lesions were detected on HAP than on unenhanced or PVP especially when the lesions were $<1 \mathrm{~cm}$ and $1-3 \mathrm{~cm}$ in size. The conspicuity of hypervascular lesions was higher on HAP than on other phases when the lesion were $<1 \mathrm{~cm}$ in size. When the lesion size was $>3 \mathrm{~cm}$, similar numbers were seen on all phases [Table/Fig-6].

\begin{tabular}{|l|c|c|}
\hline Size of the lesions & No. of lesions & Percentage (\%) \\
\hline$<1 \mathrm{~cm}$ & 45 & 22.5 \\
\hline $1-3 \mathrm{~cm}$ & 105 & 52.5 \\
\hline$>3 \mathrm{~cm}$ & 50 & 25 \\
\hline Total & 200 & 100 \\
\hline
\end{tabular}

[Table/Fig-6]: Distribution of lesions based on size of the lesions.

${ }^{*}$ Predominant lesions show size variation between $1-3 \mathrm{~cm}(52.5 \%)$

A standard of reference for each detected lesions was determined. For this purpose biopsy, results of ultrasound, MRI were collected and all patients were followed until final diagnosis was arrived. The following information was accepted as the standard of reference [Table/Fig-7]:

\begin{tabular}{|c|c|c|c|c|}
\hline Abnormality & Biopsy & USG & MRI & Follow-up \\
\hline Simple cyst (20 lesions/5 patients) & - & $20 / 5$ & - & $20 / 5$ \\
\hline Liver abscess (10 lesions/3 patients) & $10 / 3$ & $10 / 3$ & - & $10 / 3$ \\
\hline Haemangioma (24 lesions/10 patients) & - & - & $24 / 10$ & $24 / 10$ \\
\hline FNH (2 lesion/2 patient ) & $2 / 2$ & - & - & $2 / 2$ \\
\hline Adenoma (1 lesion/1 patient) & $1 / 1$ & - & - & $1 / 1$ \\
\hline HCC (26 lesions/12 patients) & 26/12 & - & - & $26 / 12$ \\
\hline Metastases (113 lesions/25 patients) & $70 / 25$ & - & - & $113 / 25$ \\
\hline Intrahepatic CCA (2 lesion/2 patient) & $2 / 2$ & - & - & $2 / 2$ \\
\hline \multicolumn{5}{|c|}{$\begin{array}{l}\text { [Table/Fig-7]: Standard of reference in } 198 \text { lesions detected on Triple phase CT } \\
\text { scan liver. } \\
\text { USG: Ultrasonography; MRI: Magnetic resonance imaging, СT: Computed tomography }\end{array}$} \\
\hline
\end{tabular}

Findings of percutaneous biopsy: If in a patient with multiple lesions, biopsy was performed for one lesion; all lesions with the same appearance at CT as the biopsied lesion were considered to represent the same pathologic finding.

Findings at ultrasound: An anechoic lesion with posterior enhancement was considered as proof of a cyst.

Findings at MRI: Sharp well demarcated hypointense signal on $\mathrm{T} 1$ weighted images and homogenously hyperintense signal on T2 weighted images was considered as a proof for haemangioma.

Findings at follow-up: When patients with proved malignancy developed a solid lesion in liver that increased in size over time, the lesions were considered as metastasis or primary tumour. Conversely, if a lesion did not show any change after a minimum follow-up of 6 months-1 year, the lesion was considered to be benign.

Overall, there were 11 enhancement patterns, five were hypovascular enhancing patterns. The five hypovascular enhancing patterns were hypo/hypo (cyst)/hypo, hyper (rim)/hypo (cyst)/hypo, hypo/ hypo/hypo, hyper (rim)/hypo/hypo, and hypo/hypo/hyper [Table/ Fig-8]. Of the 11 enhancement patterns, six were hypervascular enhancing patterns. The six hypervascular enhancement patterns were A (puddles)/A/A, A/A/A(cleft), A (Variegated)/A/A(capsule), hyper (incomplete)/A/A and Hyper/A/A, and mixed/mixed/mixed [Table/Fig-9].

Out of 11 enhancement patterns, six patterns were found in benign lesions. Out of six, four patterns were highly specific for benign liver lesions hypo/hypo/hypo, hypo (rim), hypo, A (puddles)/A/A, A/A/A (cleft) [Table/Fig-10].

Out of total 11 enhancement patterns, eight enhancement patterns were found in malignant lesions. Four enhancement patterns were highly specific for malignant lesions hypo/hypo/hypo, hypo (rim)/hypo/ hypo, A (variegated)/AVA, hyper (incomplete)/AVA [Table/Fig-11].

In the present study, the triple phase CT enhancement patterns were $100 \%$ sensitive and specific in diagnosing all cases of cysts, abscess, 


\begin{tabular}{|c|c|c|c|c|c|c|c|c|c|}
\hline \multicolumn{3}{|c|}{ Enhancement pattern } & \multirow[b]{2}{*}{ Total no. of lesions in each pattern } & \multicolumn{3}{|c|}{ Malignant lesions } & \multicolumn{3}{|c|}{ Benign lesions } \\
\hline HAP & PVP & DP & & No & $\%$ & Final diagnosis & No & $\%$ & Final diagnosis \\
\hline Нуро & hypo (cyst) & hypo & $n=20$ & & & & 20 & 100 & Cyst \\
\hline Hyper (rim) & Hypo (cyst) & hypo & $n=10$ & & & & 10 & 100 & Abscess \\
\hline hypo & hypo & hypo & $n=55$ & 54 & 98 & Metastasis & 1 & 2 & Haemangioma \\
\hline Hyper (rim) & hypo & hypo & $n=20$ & 20 & 100 & Metastasis & & & \\
\hline hypo & hypo & hyper & $n=5$ & 04 & 80 & Metastasis & 1 & 20 & Haemangioma \\
\hline
\end{tabular}

[Table/Fig-8]: Different hypovascular enhancement patterns and their final diagnosis $(n=110)$.

HAP: Hepatic arterial phase; PVP- Portal venous phase; DP: Delayed phase; Area of water attenuation, homogenous: hypo (cyst); Area of soft tissue attenuation, slightly in homogenous: hypo; Area of mixed attenuation but hypo attenuating due to the arterial system: mixed; Area of hyper attenuation but less than the arterial system: hyper; Iso attenuating compared to the arterial system: arterial Or A

\begin{tabular}{|c|c|c|c|c|c|c|c|c|c|}
\hline \multicolumn{3}{|c|}{ Enhancement pattern } & \multirow{2}{*}{ Total no } & \multicolumn{3}{|c|}{ Malignant lesions } & \multicolumn{3}{|c|}{ Benign lesions } \\
\hline HAP & PVP & DP & & No & $\%$ & Final diagnosis & No & $\%$ & Final diagnosis \\
\hline A (puddles) & A & A & $n=24$ & & & & 24 & 100 & Haemangioma \\
\hline A & A & A (cleft) & $\mathrm{n}=02$ & & & & 02 & 100 & $\mathrm{FNH}$ \\
\hline A (variegated) & A & A (capsule) & $n=20$ & 20 & 100 & $\mathrm{HCC}$ & & & \\
\hline Hyper (incomplete) & A & A & $\mathrm{n}=02$ & 02 & 100 & CCA & & & \\
\hline mixed & mixed & mixed & $n=23$ & 23 & 100 & Metastasis & & & \\
\hline Hyper & A & A & $n=16$ & 06 & 37 & $\mathrm{HCC}$ & 01 & 7 & Adenoma \\
\hline & & & & 09 & 57 & Metastasis & & & \\
\hline
\end{tabular}

[Table/Fig-9]: Different hypervascular enhancement patterns and their final diagnosis. $(n=87)$.

HAP: Hepatic arterial phase; PVP: Portal venous phase; DP: Delayed phase; Area of water attenuation, homogenous: hypo (cyst); Area of soft tissue attenuation, slightly in homogenous: hypo; Area of mixed attenuation but hypo attenuating due to the arterial system: mixed; Area of hyper attenuation but less than; the arterial system: hyper; Iso attenuating compared to the arterial system: arterial Or A

\begin{tabular}{|c|c|c|c|c|c|}
\hline \multirow[b]{2}{*}{ Final diagnosis } & \multirow{2}{*}{$\begin{array}{l}\text { No. of } \\
\text { lesions }\end{array}$} & \multirow[b]{2}{*}{$\%$} & \multicolumn{3}{|c|}{ Enhancement pattern } \\
\hline & & & HAP & PVP & DP \\
\hline Cyst $(n=20)$ & 20 & 100 & Нyро & Hypo (Cyst) & Нypo \\
\hline Abscess $(n=10)$ & 10 & 100 & Hypo (Rim) & Hypo (Cyst) & Нypo \\
\hline \multirow{3}{*}{ Haemangioma $(n=26)$} & 24 & 92.3 & A (Puddles) & A & A \\
\hline & 1 & 3.84 & Нyро & Hypo & Нypo \\
\hline & 1 & 3.84 & Нypo & Hypo & Hyper \\
\hline $\mathrm{FNH}(\mathrm{n}=2)$ & 2 & 100 & A & A & $A$ (Cleft) \\
\hline Adenoma $(n=1)$ & 1 & 100 & Hyper & A & A \\
\hline \multicolumn{6}{|c|}{$\begin{array}{l}\text { [Table/Fig-10]: Different enhancement patterns identified in benign lesions in the } \\
\text { present study. } \\
\text { *FNH: Focal nodular hyperplasia; *Area of water attenuation, homogenous: hypo (cyst); Area } \\
\text { of soft tissue attenuation, slightly in homogenous: hypo Area of mixed attenuation but hypo } \\
\text { attenuating due to the arterial system: mixed; Area of hyper attenuation but less than the arterial } \\
\text { system: hyper; Iso attenuating compared to the arterial system: arterial Or A }\end{array}$} \\
\hline
\end{tabular}

$\mathrm{FNH}$, adenoma and intrahepatic cholangiocarcinoma. The sensitivity of triphasic CT enhancement patterns in diagnosis of HCC $(79.9 \%)$, haemangioma (91.6\%) and metastasis (91.15\%). There was $100 \%$ specificity in diagnosing all the cases only when the individual lesions had typical enhancement pattern [Table/Fig-12]

\section{DISCUSSION}

The present study includes 60 patients of age between 20-80 years. The predominant age group in the present study was 51-60 years accounting to $33 \%$, followed by $41-50$ years accounting to $23 \%$ which is identical to the similar studies conducted by Ahirwar CP

\begin{tabular}{|c|c|c|c|c|c|}
\hline \multirow[b]{2}{*}{ Final diagnosis } & \multirow{2}{*}{$\begin{array}{l}\text { No. of } \\
\text { lesions }\end{array}$} & \multirow[b]{2}{*}{$\%$} & \multicolumn{3}{|c|}{ Enhancement patterns } \\
\hline & & & HAP & PVP & DP \\
\hline \multirow{5}{*}{$\begin{array}{l}\text { Metastasis } \\
(n=113)\end{array}$} & 55 & 48.6 & Hypo & Hypo & Нypo \\
\hline & 20 & 17.6 & Hypo (RIM) & Нypo & Нypo \\
\hline & 23 & 20.3 & Mixed & Mixed & Mixed \\
\hline & 09 & 8.84 & Hyper hypo & A & A \\
\hline & 05 & 4.42 & & Нypo & Hyper \\
\hline \multirow{2}{*}{$\operatorname{HCC}(n=26)$} & 20 & 76.92 & A (Varigated) & A & A (Capsule) \\
\hline & 06 & 23.07 & Hyper & A & A \\
\hline $\begin{array}{l}\text { Intrahepatic CCA } \\
(\mathrm{n}=2)\end{array}$ & 2 & 100 & $\begin{array}{c}\text { Hyper } \\
\text { (Incomplete) }\end{array}$ & A & A \\
\hline \multicolumn{6}{|c|}{$\begin{array}{l}\text { [Table/Fig-11]: Different enhancement patterns identified in malignant lesions in } \\
\text { the present study. } \\
\text { *HCC-Hepatocellular carcinoma; CCA: Cholangiocarcinoma; ; Area of water attenuation; homogenous: } \\
\text { hypo (cyst); Area of soft tissue attenuation, slightly in homogenous: hypo; Area of mixed attenuation but } \\
\text { hypo attenuating due to the arterial system: mixed; Area of hyper attenuation but less than; the arterial } \\
\text { system: hyper; Iso attenuating compared to the arterial system: arterial Or A }\end{array}$} \\
\hline
\end{tabular}

et al., Abbas KA et al., with 51-60 years as predominant age group $[5,6]$. There were 35 males and 25 females in the present study which is consistent with other similar studies like Ahirwar CP et al., Abbas KA et al., and Kamlesh $\mathrm{G}$ et al., showing male predominance at $54 \%, 51.5 \%$ and $59 \%,[5,6,7]$.

There was male preponderance in metastases (58\%) and intrahepatic CCA (100\%) and abscess (100\%) when compared to females. There was female preponderance in Haemangioma (60\%) and FNH (100\%). Simple cyst, adenoma and HCC were seen

\begin{tabular}{|l|c|c|c|c|c|c|c|c|c|c|}
\hline Diagnosis & TP & FP & FN & TN & Total & SEN & SPF & PPV & NPV & Accuracy \\
\hline Simple cyst & 20 & 0 & 0 & 180 & 200 & $100 \%$ & $100 \%$ & $100 \%$ & $100 \%$ & $100 \%$ \\
\hline Liver abscess & 10 & 0 & 0 & 190 & 200 & $100 \%$ & $100 \%$ & $100 \%$ & $100 \%$ & $100 \%$ \\
\hline Haemangioma & 22 & 0 & 2 & 176 & 200 & $91.66 \%$ & $100 \%$ & $100 \%$ & $98.87 \%$ & $99 \%$ \\
\hline FNH & 2 & 0 & 0 & 198 & 200 & $100 \%$ & $100 \%$ & $100 \%$ & $100 \%$ & $100 \%$ \\
\hline Adenoma & 1 & 0 & 0 & 199 & 200 & $100 \%$ & $100 \%$ & $100 \%$ & $100 \%$ & $100 \%$ \\
\hline HCC & 20 & 0 & 06 & 174 & 200 & $79.92 \%$ & $100 \%$ & $100 \%$ & $96.66 \%$ & $97.00 \%$ \\
\hline Metastasis & 103 & 0 & 10 & 87 & 200 & $91.15 \%$ & $100 \%$ & $100 \%$ & $89.69 \%$ & $95.00 \%$ \\
\hline Intrahepatic CCA & 2 & 0 & 0 & 198 & 200 & $100 \%$ & $100 \%$ & $100 \%$ & $100 \%$ & $100 \%$ \\
\hline
\end{tabular}


equally distributed among both sexes. All cases of abscess and intrahepatic cholangiocarcinoma (100\%) were seen in males.

Regarding the detection of lesions in different phases of triple phase CT scan liver, the present study is well in consistent with other studies like Francis IR, Soyer $\mathrm{P}$ and Miller FH et al., where in most small sized hypovascular lesions were best detected during PVP and hypervascular lesions in HAP [8-10].

In the present study, lesions of size $<3 \mathrm{~cm}$ showed lower sensitivity in identification on unenhanced scans because of difficulty in differentiating it from unenhanced vessels and biliary dilatation. The same size hypovascular lesions were better visualised on PVP and hypervascular lesions on HAP with statistical significance. Lesions of size $>3 \mathrm{~cm}$ are visualised better in all phases of scan including unenhanced and so shows no statistical difference between them.

We used a size cut-off of $<1 \mathrm{~cm}, 1-3 \mathrm{~cm}$ and $>3 \mathrm{~cm}$ and showed statistical significance at $<3 \mathrm{~cm}$ size whereas Miller $\mathrm{FH}$ et al., divided the lesion sizes into four categories i.e., $<1 \mathrm{~cm}, 1-2 \mathrm{~cm}, 2-3 \mathrm{~cm}$ and $>3 \mathrm{~cm}$ and showed similar findings with statistical significance at size $<2 \mathrm{~cm}$ in malignant hypovascular and hypervascular lesions [10].

The present study showed higher frequency of hypovascular lesions at $56 \%$ which is identical to many similar studies like Ahirwar CP et al., Kamlesh G et al., Van Leeuwen MS et al., Divya B et al., and Hafeez $\mathrm{S}$ et al., which also showed predominant hypovascular lesions at 57\%, 75\%, 60\%, 62\% and 61\%, [5,7,11,12,13].

Characterising hypovascular lesions in the present study is in consistent with other similar studies like Van Leeuwen MS et al., on 94 patients [11], Ahiwar CP et al., Kamlesh G et al., Divya B et al., and Hafeez $\mathrm{S}$ et al., wherein based on enhancement patterns, 20 lesions with "Hypo(cyst)/Hypo/Hypo pattern" with sharp margins and homogenous vascular pattern were diagnosed as "cysts"; 10 lesions with "Hyper (rim)/Hypo(Cyst)/Hypo pattern" as "abscess" $[5,7,12,13]$.

Particular in non-cystic hypovascular lesions: "Hypo/ Hypo/ Hypo pattern" is seen in 54 (98\%) metastasis and 1 (2\%) atypical haemangioma.

Characterising hypervascular lesions in the present study is in consistent with other similar studies like Ahirwar CP et al., Kamlesh G et al., Van Leeuwen MS et al., Divya B et al., and Hafeez $S$ et al., wherein based on enhancement patterns, 24 lesions with "A(puddles)/ A/A pattern" were diagnosed as "haemangiomas"; two lesions with "AVAA(cleft) pattern" as "FNH", two lesions with "Hyper (incomplete)/ A A pattern" as "Intrahepatic Cholangiocarcinoma" [5,7,11-13].

Particular in non-cystic hypovascular lesions-"Hypo/Hypo/ Hypo pattern" is seen in 54 (98\%) metastasis and 1 (2\%) atypical hemangioma. Twenty of $26 \mathrm{HCC}$ showed "variegated/A/A(delayed) pattern", 23 of 23 metastasis showed "mixed/mixed/mixed pattern".

The studies conducted by Van Leeuwen MS et al., on 94 patients showed 11 enhancement patterns similar to the present study but with 6/11 always due to benign disease, 3/11 always due to malignant and 2/11 due to metastasis and haemangioma, where as in the present study $4 / 11$ due to benign disease, 5/11 due to malignant and 2/11 due to both malignant and benign lesions [11]. Above findings were similar to the study conducted by Gualdi GF et al., where in (Hypo/Hyper/Hyper, Hyper/lso/lso, Hyper/Hyper/lso, and Hyper/Hyper/Hyper) patterns were always referable to benign disease(haemangioma, FNH and adenoma), (Iso/Hypo/Hypo, Iso/ Iso/Hypo, Hyper/Hypo/Hypo, and Hyper/Hyper/Hypo) were always referable to malignant disease (hepatocellular carcinoma-HCCmetastases), (Hypo/Hypo/Hypo, Hypo/Hypo/Hyper, and Hyper/A/A) were seen in both benign and malignant diseases [14].

Histologic examination, correlative imaging, or clinical or imaging follow-ups were used as the standards of reference. It was observed that $92 \%$ of the 100 lesions demonstrated arterial phase enhancement. The patterns associated with PPV of $82 \%$ or more and specificity of $80 \%$ or more included abnormal internal vessels or variegated (HCC), peripheral puddles (Haemangiomas), and complete ring (Metastases). It was concluded that focal hepatic lesions in arterial phase of enhancement has potential use in determination of specific diagnosis.

\section{Benign Liver Lesions Detected in the Present Study} Haemangioma: There were total 26 lesions in /10 patients (8 females +2 males) diagnosed with hemangioma. Majority of size $<6 \mathrm{~cm}$ and hypodense on plain CT scan. Out of total 26 lesions, 24 lesions showed arterial phase enhancement with early discontinuous peripheral nodular enhancement (while 2/26 atypical haemangioma showed hypo dense pattern) with progressive centripetal filling in PVP and delayed enhancement in equilibrium phase. Absence of contrast washout in DP and nodular peripheral centripetal enhancement helps in differentiating from hypervascular metastasis [Table/Fig-13].
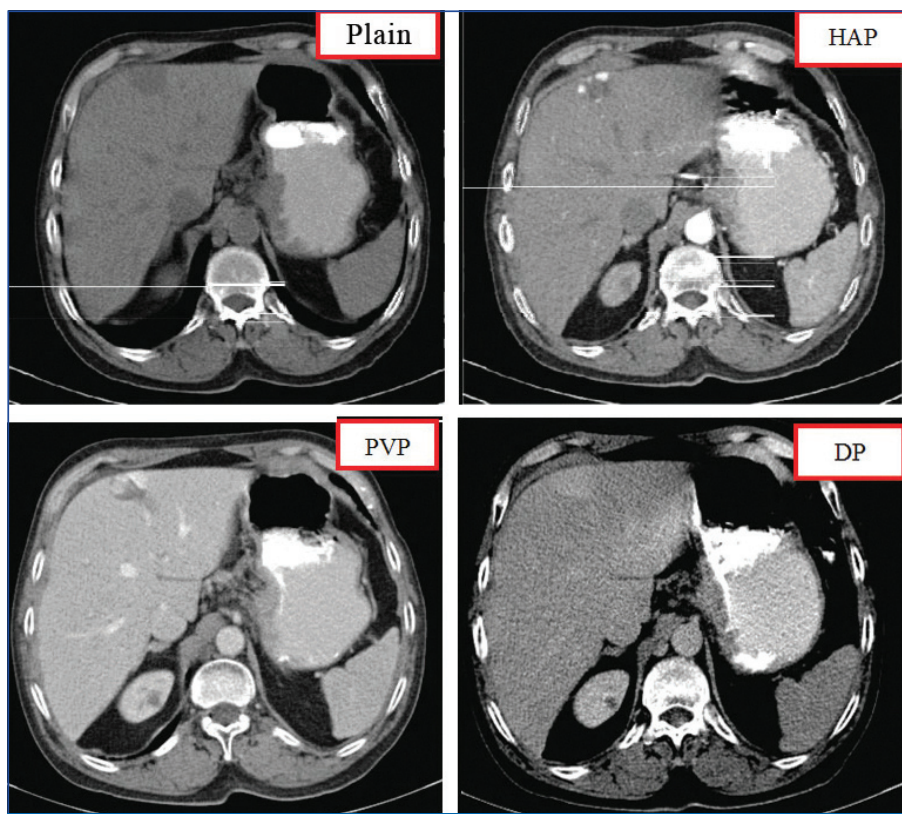

[Table/Fig-13]: Triple phase CT scan liver showing "Haemangioma" Triple phase CTHaemangioma: 1. Plain-Hypo; 2. HAP-Arterial (Periphearl puddling); 3. PVP-Arterial 4. DP-Arterial

A total of three patterns were identified where in 24/26 patients showed typical "A(puddling)/AVA pattern" and rest two were misdiagnosed as metastasis on CT scan which showed "Hypo/ Hypo/ Hypo" and "Hypo/ Hypo/ Hyper" patterns, confirmed as Atypical haemangioma on biopsy. The two missed lesions showed background cirrhosis, which usually alters the morphology of Hemangioma and the reason for false positive diagnosis (consistent with Yun EJ et al., findings [15].

Overall Contrast CT showed $92.3 \%$ sensitivity, 100\% specificity with a diagnostic accuracy of $99 \%$ for detection and characterisation of haemangiom in this study.

Hepatic adenoma: One case of hepatic adenoma was diagnosed in 36-year-old female with h/o hepatitis B since four years with a well-defined hypoechoic capsule on USG and diagnosed as HCC. Lesion showed hyperdense on plain CT and "Hyper/Iso/Iso pattern" on contrast CT. Biopsy was done and final diagnosis was Hepatic adenoma.

Capsule can be present in both HCC and Adenoma and should not be used as differentiation criteria. Van den Esschert Jw et al., Grazioli $L$ et al., showed that $25 \%$ of hepatic adenomas may show thin tumour capsule $[16,17]$.

Focal nodular hyperplasia: Both two cases in the present study were middle aged females and demonstrated well-defined margins (100\%). In 38-year-old female with h/o Carcinoma (Ca) thyroid showed hypoechoic lesion in liver and was diagnosed as metastatic deposit on USG. On triple phase, the lesion showed "A/Iso/Iso pattern "with enhancing central scar in delayed scans [Table/Fig-14]. The diagnosis 

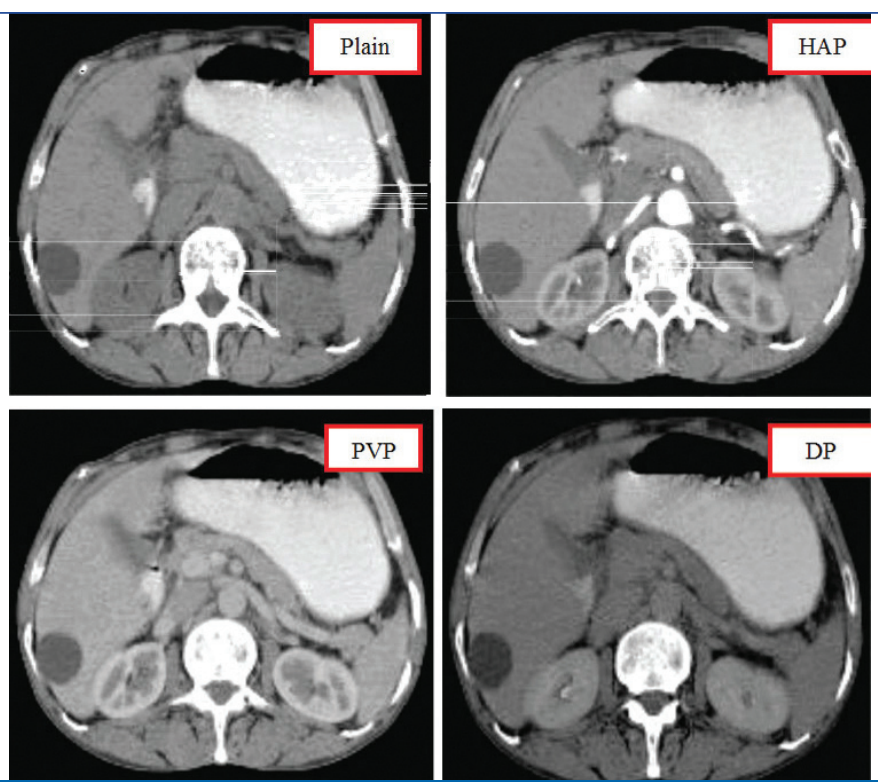

[Table/Fig-14]: Triple phase CT scan liver showing "Focal Nodular Hyperplas a" Triple phase CT-FNH: 1. Plain- Hypo (solid); 2. HAP- Homogenous enhance. 3. DP-

Delayed central scar enhance.

of FNH given on Contrast CT were confirmed on histopathology. In another 25-year-old female, hypoechoic lesion is noted on USG and diagnosed as Haemangioma, where in triple phase CT showed "ANA Iso pattern" was misdiagnosed as another benign lesion as central scar is not prominently seen but on histopathology $\mathrm{FNH}$ diagnosis was given. Hence, in small lesions of $\mathrm{FNH}$ scar may not be visualised. Ruppert-kohlmayr AJ et al., and Brancatelli G et al., studies observed the contrast enhancement variations in $\mathrm{FNH}$ discussing the typical and atypical appearances of $\mathrm{FNH}[18,19]$.

Liver abscess: Liver abscess was diagnosed in total 10 lesions in three patients (all male patients). All lesions were hypodense on plain CT and showed "Hyper (rim)/Hypo/Hypo pattern" on contrast CT, two patients showed typical double target pattern of enhancement with "central hypo/enhancing rim/outermost hypo". The typical enhancement pattern is 100\% sensitive and specific in Radin RD et al., study as well as in present study [20].

Simple cyst of liver: Simple cyst was diagnosed in total 20 lesions/5 patients ( 4 females and 1 male). All lesions were hypodense on plain CT and showed homogenous water attenuation (<20 HU) with "Hypo (Cyst)/Hypo/Hypo pattern" with no wall enhancement on contrast CT [Table/Fig-15]. This enhancement pattern is 100\% sensitive and specific in diagnosing simple cyst of liver. Barnes PA et al., described the hyperdense cyst $(>2 \mathrm{HU})$, possibly haemorrhagic diagnostic difficulty in differentiating from metastasis arising from cystic carcinomas [21].

Malignant Liver Lesions Detected in the Present Study Hepatocellular carcinoma: HCC was diagnosed in 12 patients/5160 year predominant age group with youngest at 42 year and oldest at 66 year/male preponderance in 10 out of 12 cases noted [Table/Fig-16].

Out of total 12 lesions, 11 showed well-defined margins while one showed irregular margin. Eight lesions from these 12 were hypodense on plain CT. Early enhancement with rapid washout in PVP and DP is characteristic pattern of enhancement and sometimes capsule may show DP enhancement as described by Lee $\mathrm{KHY}$ et al., and nine out of 12 cases showed tumour thrombus in portal vein as described by Karhunen PJ [22,23]. Thus, along with diagnosis, triple phase gives additional information on vascular invasion, arterio-portal shunt, and capsular delineation and provides vascular roadmap for presurgical evaluation.

Karhunen PJ, showed that hypervascularity in PVP was found in well differentiated $\mathrm{HCC}$ and portal vein invasion was frequently
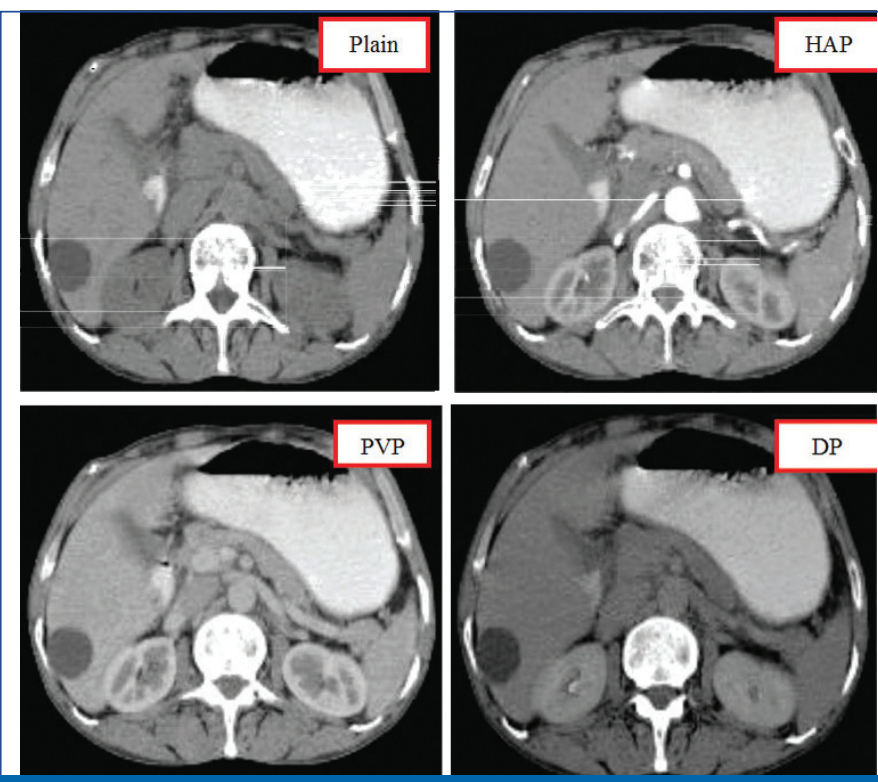

[Table/Fig-15]: Triple phase CT scan liver showing "Simple Liver Cyst" Triple phase CT-Liver Cyst: 1. Plain-Hypo.(cyst); 2. HAP-Hypo; 3. PVP-Hypo; 4. DP-Hypo
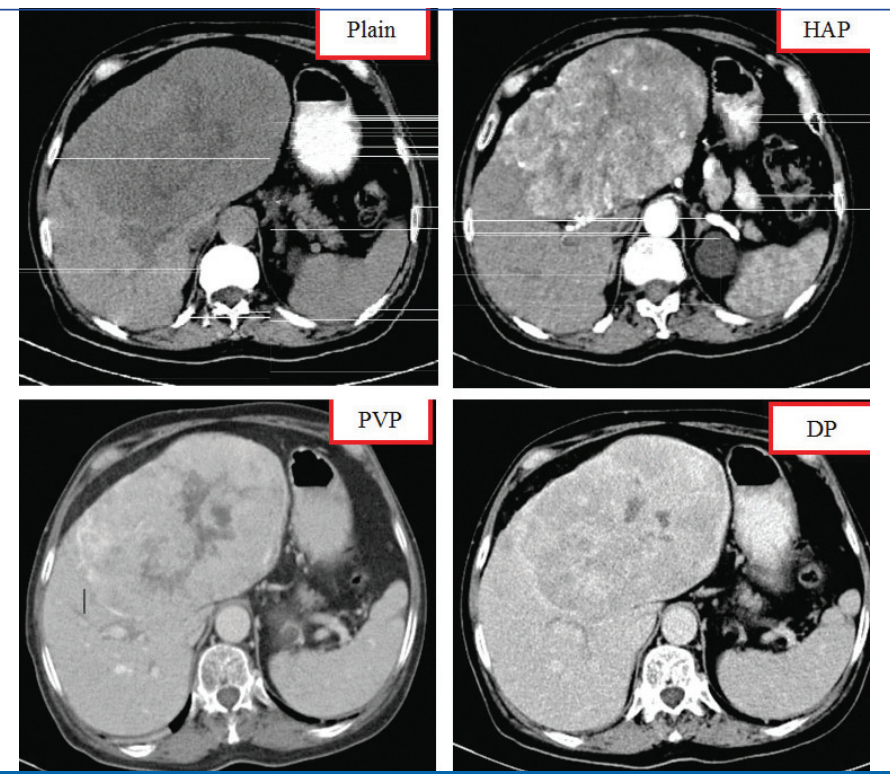

[Table/Fig-16]: Triple phase CT scan liver showing "Hepatocellular Carcinoma" Triple phase CT-HCC: 1. Plain-Hypo/Hetero.(Solid); 2. HAP-Variegated enhance; 3. PVP-Wash out; 4. DP-Delayed capsule enhance.

seen in HCC of size $>10 \mathrm{~cm}$ [23]. Lee KHY et al., described the typical appearance of HCC including intralesional contrast washout [22]. Choi Bl et al., and Kitao A et al., showed non-smooth tumour margin in pre-operative CT had a statistically significant association with microvascular invasion [24,25]. More aggressive treatment should be considered in HCC patients with suspected positive microvascular invasion.

Cholangiocarcinoma: Intrahepatic CCA was diagnosed in two patients (all males, age $>60$ years). Two cases had jaundice and hyper bilirubinemia at presentation (100\%). Both had a single lesion each, which is subscapular and had capsular retraction (100\%), hypodense on plain CT and no enhancement in HAP and PVP but enhanced in DP (100\%) [Table/Fig-17].

Metastasis: Metastasis was diagnosed on 25 patients with secondary metastasis with predominant age group 51-60 (60\%). The most common primary is lung $\mathrm{Ca}$, followed by Ca of stomach. Youngest was 32-year-old female and oldest was 76-year-old male with $\mathrm{Ca}$ stomach. Male preponderance was noted in 15 patients (60\%). Hypovascular lesions are more common accounting to $71 \%$ of all hypovascular lesions. Hypervascular lesions account to $37 \%$ of all hypervascular lesions and metastasis mostly from RCC and Thyroid carcinoma. 

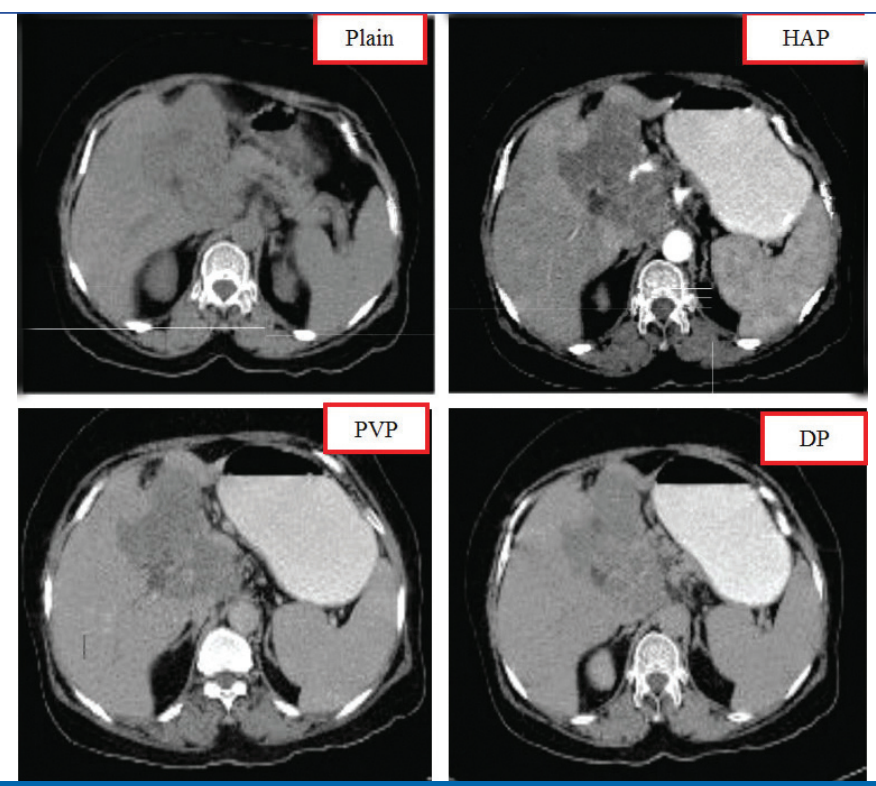

[Table/Fig-17]: Triple phase CT scan liver showing "Intrahepatic Cholangiocarcinoma" Triple phase CT- IH-CCA: 1. Plain- Hypo/Hetero.(Solid); 2. HAP- Incomplete enhance; 3. PVP-Arterial; 4. DP-Arterial enhance.

Out of total 25 patients, 22 patients showed well-defined margins, 12 patients demonstrated HAP enhancement-partial in five and complete in seven patients. Eighteen out of these 25 cases showed PVP enhancement but all of them showed rapid wash-out of contrast and hypodense in DP [Table/Fig-18,19].
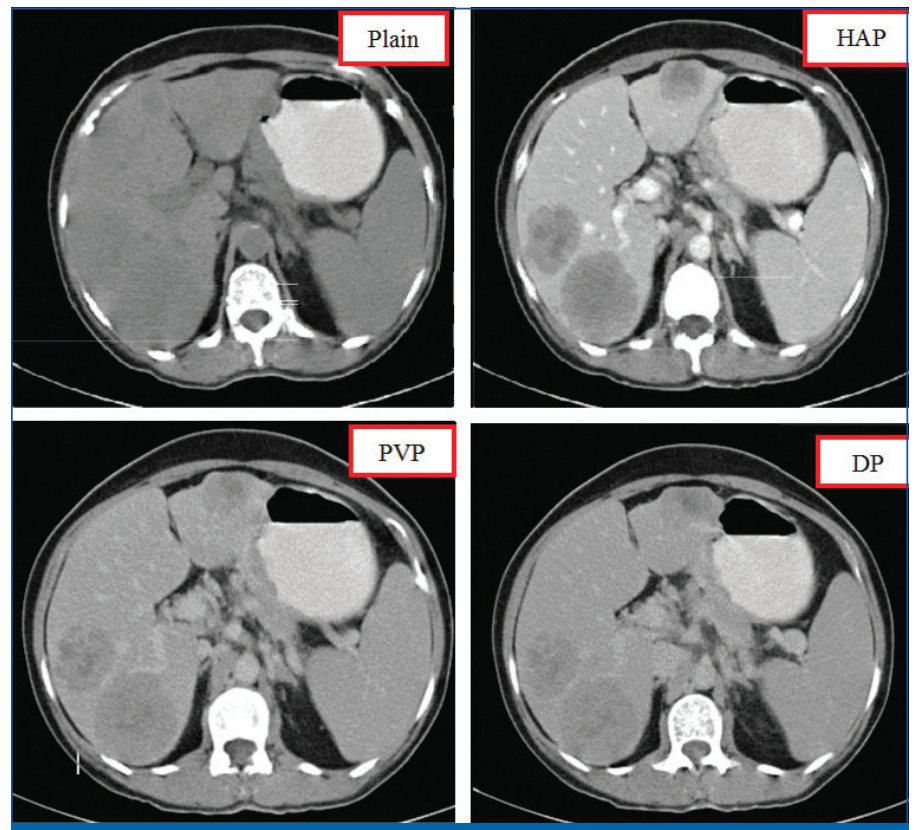

[Table/Fig-18]: Triple phase CT scan liver showing "Metastasis" Triple phase CTMetastasis: 1. Plain- Hypo/Hetero.(Solid); 2. HAP- Mixed; 3. PVP-Mixed; 4. DP-Mixed.

\section{Limitation(s)}

The present study used conventional MRI sequences in assessing liver lesion.

\section{CONCLUSION(S)}

We recommend Triple phase CT scan as a standard first line procedure with high sensitivity, specificity and accuracy in differentiating benign and malignant liver lesions and avoiding unnecessary biopsies. Particularly in HCC, triple phase CT provides additional information of vascular invasions, Arterioportal shunts, capsular delineation and vascular road map for presurgical evaluation. HAP is used in identifying small hypervascular lesions and PVP in detecting small hypovascular lesions. As liver imaging is fast evolving, we recommend further large research studies to compare the efficacy of triple phase computed tomography with advanced MRI liver imaging techniques.
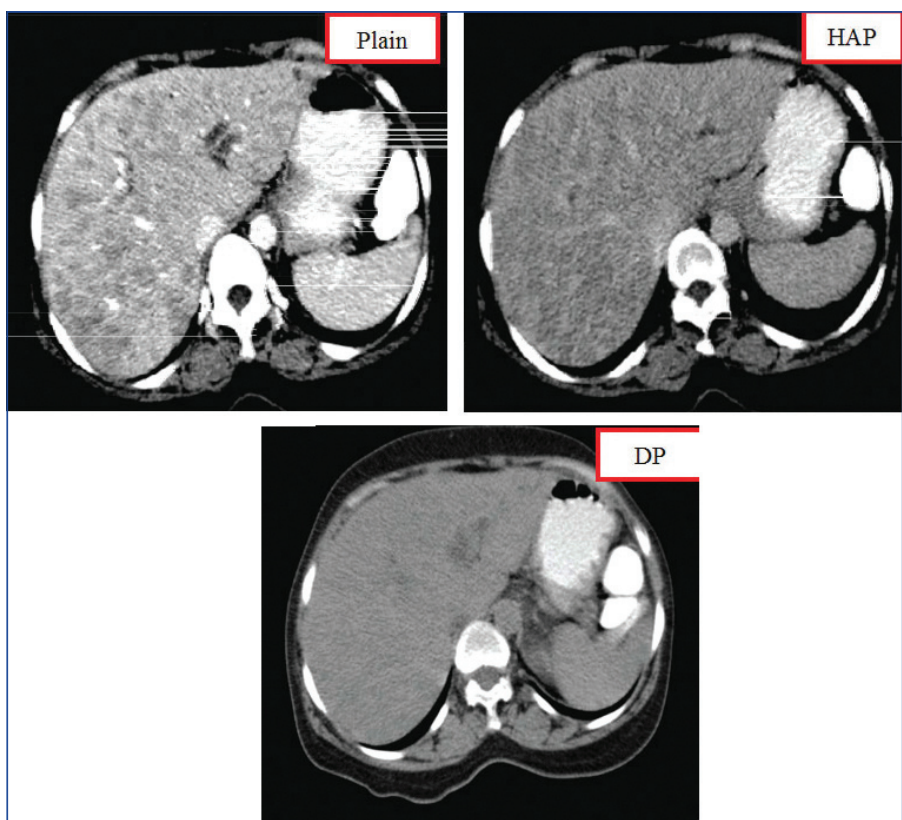

[Table/Fig-19]: Triple phase CT scan liver showing "Metas Metastasis: 1. HAP- Hypo. 2. PVP- Hypo 3. DP-Hypo.

\section{REFERENCES}

[1] Moore, Keith L, Anne MR. Essential Clinical Anatomy, $3^{\text {rd }}$ Edition. Toronto (Canada): Lippincott Williams \& Wilkins; 2007.

[2] Ros PR, Ertuk SM. Malignant liver tumours. In: Gore RM, Levine MS: Text book of Gastrointestinal radiology, Vol 2, $4^{\text {th }}$ Edition. Philadelphia/Saunders; 2008; 1623-62.

[3] Jang HJ, Kim TK, Lim HK, Hepatic hemangioma: Atypical appearances on CT, MR imaging, and sonography. AJR Am J Roentgenol. 2003;180:135-41.

[4] Kawata S, Murakami T, Kim T, Hori M, Fedrele MP, Kumano S, et al. Multidetector CT: Diagnosis impact of slice thickness on detection of hypervascular hepatocellular carcinoma. AJR Am J Roentgenol. 2002;179:61-66.

[5] Ahirwar CP, Patil A, Soni N. Role of triple phase computed tomography for evaluation of hepatic lesions. Int J Res Med Sci 2016;4:3576-83.

[6] Abbas KA, Caroline AE, Edward R. Triple phase CT Hounsfield \& pattern in differentiation of liver lesions. Journal of Dental \& Medical Sciences. 2017;16(01):120-25

[7] Kamlesh G, Neelam G, Garima R. Role of computed tomography in evaluation of parenchymal lesions of liver. Journal of Medical \& Dental Sciences. 2015;4(36):6257-68.

[8] Francis IR, Cohan RH, McNulty NJ, Platt JF, Korobkin M, Gebremariam A, et al, Multidetector CT of liver and hepatic neoplasms: Effect of multiphasic imaging on tumour conspicuity and vascular enhancement. AJR. 2003;180:1217-24.

[9] Soyer P, Poccard M, Boudiaf M, Abitbol M, Hamzi L, Panis Y, et al. Detection of hypovascualar hepatic metastases at triple phase helical CT: Sensitivity of phases and comparison with surgical and histopathologic findings. Radiology. 2004;231:413-20.

[10] Miller FH, Butler RS, Hoff FL, Fitzgerald SW, Nemcek AA, Gore RM, et al. using Triphasic helical CT to detect focal liver lesions in patients with neoplasms. AJR. 1998;171:643-49.

[11] Van Leeuwen MS, Noordzij J, Felberg MAM, Hennipman AH, Doornewaard $\mathrm{H}$. Focal liver lesions: Characterisation with triphasic spiral CT. Radiology. 1996;201(2):327-36.

[12] Divya B, Reena M, Avinash G, Sumitra C, Jaya P. Role of triple phase CT in the evaluation of liver lesions. International Journal of Current Research. 2017;9(03):48075-78

[13] Hafeez S, Alam M, Sajjad Z, Akhter W, Mubarak F. Triple phase Computed tomography (CT) scan in Focal liver lesions. Journal of Pakistan Medica Association. 2012;61(6):571-75.

[14] Gualdi GF, Casciani E, D’Agostino A, Polettini E. Triphasic spiral computerized tomography of the liver: Vascular models of non-cystic focal lesions. Radiol Med. 1998;96(4):344-52.

[15] Yun EJ, Choi BI, Han JK, Jang HJ, Kim TK, Yeon KM, et al. Hepatic hemangioma contrast-enhancement pattern during the arterial and portal venous phases of spiral CT. Abdom Imaging. 1999;24:262-66.

[16] Van den Esschert JW, van Guilik TM, Phoa SS. Imaging modalities for focal nodular hyperplasia and hepatocellular adenoma. Dig Surg. 2010;27(1):46-55.

[17] Grazioli L, Federle MP, Brancatelli G, Ichikawa T, Olivetti L, Blachar A Hepatic adenomas: Imaging and pathologic findings. Radiographics. 2001;21(4):877-92

[18] Ruppert-Kohlmayr AJ, Uggowitzer MM, Kugler C, Zebedin D, Schaffler G Ruppert GS. Focal nodular hyperplasia and hepatocellular adenoma of the liver: Differentiation with multiphasic helical CT. American Journal of Roentgenology. 2001;176(6):1493-98

[19] Brancatelli G, Federle MP, Grazioli L, Blachar A, Peterson MS, Thaete L. Foca nodular hyperplasia: CT findings with emphasis on multiphasic helical CT in 78 patients. Radiology. 2001;219(1):61-68 
[20] Radin RD, Ralls PW, Colletti PM, Hallis JM. CT of amoebic liver abscesses. AJR Am J Roentgenol. 2000;150(6):1297-301.

[21] Barnes PA, Thomas JL, Bernardino ME, pitfalls in the diagnosis of hepatic cysts by computed tomography. Radiology. 2002;141:129-33.

[22] Lee KHY,' Malley MEO, Haider MA, Hanbidge A. Triple-phase MDCT of HCC. AJR. 2004;182:643-49.

[23] Karhunen PJ. Benign hepatic tumour and tumour-like conditions in man. J Clin Pathol. 1986;39(2):183-88.
[24] Choi BI, Lee HJ, Han JK, Choi DS, Seo JB, Han MC. Detection of hypervascular nodular hepatocellular carcinomas value of Triphasic helical CT compared with iodized-oil CT. AJR Am J Roentgenol. 1997;168:219-24.

[25] Kitao A, Matsui O, Yoneda N, Kita R, Kozaka K, Kobayashi S, Gabata T. Differentiation between hepatocellular carcinoma showing hyper intensity on the hepatobiliary phase of gadoxetic acid-enhanced MRI and focal nodular hyperplasia by CT and MRI. American Journal of Roentgenology. 2018;211(2):347-57.

\section{PARTICULARS OF CONTRIBUTORS:}

1. Associate Professor, Department of Radiodiagnosis, Kamineni Institute of Medical Sciences, Narketpally, Hyderabad, Telangana, India

2. Resident, Department of Radiodiagnosis, Kamineni Institute of Medical Sciences, Narketpally, Hyderabad, Telangana, India.

3. Resident, Department of Radiodiagnosis, Kamineni Institute of Medical Sciences, Narketpally, Nalgonda, Telangana, India.

NAME, ADDRESS, E-MAIL ID OF THE CORRESPONDING AUTHOR:

Venkat Kishan Tatikonda,

1-2-234/25, Plot No-12G, SBH Colony, Domalguda, Hyderabad, Telangana, India

E-mail: venkatkishanresearch@gmail.com

\section{AUTHOR DECLARATION:}

- Financial or Other Competing Interests: None

- Was Ethics Committee Approval obtained for this study? Yes

- Was informed consent obtained from the subjects involved in the study? Yes

- For any images presented appropriate consent has been obtained from the subjects. Yes
PLAGIARISM CHECKING METHODS: [Jain Het al.]

- Plagiarism X-checker: Dec 29, 2020

- Manual Googling: Feb 15, 2021

- iThenticate Software: Feb 17, 2021 (8\%)
ETYMOLOGY: Author Origin

Date of Peer Review: Feb 08, 2021

Date of Acceptance: Feb 17, 2021

Date of Publishing: Apr 01, 2021 